\title{
7. Visual Generational Genres
}

\begin{abstract}
Chapter 7 considers the role of generational literacies and etiquettes around visual genres. For example in our study, younger participants tended to take and share more pictures, while older participants tended to take less but comment more on their children's images. Here, generational understandings of co-present gift giving rituals can be found.
\end{abstract}

Keywords: gift-giving; co-presence; visuality; food and travel genres

This chapter focuses on two popular genres of social media photographyfood and travel — and how families in Shanghai, Tokyo and Melbourne deploy them to partake in different forms of care at a distance (see Chapter 5 ). We consider genre as groupings of images as used by Horst and Miller $(2012,108)$, where "genre implies a combination of acceptability that is simultaneously moral, aesthetic and practical." Here the exploration of food and travel images, shared and circulated by family members are considered as part of maintaining digital kinship rhythms. Through these dominant intergenerational genres, we consider how cross-generational media literacies play out.

For example, in Japan, older participants tended not to share images as often as their younger counterparts, but they felt compelled to respond and comment on images posted by others as part of digital kinship to affirm and maintain family relationships. These older participants also felt that part of bonding with younger relatives was to acknowledge them through responding to their posts. On the other hand, younger users tended to upload more images on a regular basis, which was also found in Shanghai.

In our fieldwork, Shanghainese parents were also more likely to comment, illustrating some differences around expectations of obligation and responsiveness. And in the examples from Melbourne, sharing images of food and travel were common across wider age groups and were also reflective of lifestyle practices. In this circulation culture (as explored in Chapter 6) emergent practices_-such as non-sharing — are also playing new forms of

Hjorth, L., K. Ohashi, J. Sinanan, H. Horst, S. Pink, F. Kato, B. Zhou, Digital Media Practices in Households: Kinship through Data. Amsterdam: Amsterdam University Press, 2020 DOI 10.5117/9789462989504_CHO7 
intimate engagement. Across the three field sites, it was observable that circulating images, particularly around themes of food and travel contributed to how participants experienced family relationships.

Returning to Hochschild's (1979) notions of emotion work and feeling rules are especially helpful in considering how the circulation of images over social media platforms constitutes some of the work of the "family." That is, the kinds of labor that Erickson $(2005,338)$ describes as "activities that are concerned with the enhancement of others' emotional well-being and with the provision of emotional support." Significant to the study of emotions, gender and family life, Hochschild $(1979,561)$ has theorized emotion work as "the act of trying to change in degree or quality an emotion or feeling." She identifies how techniques of emotion work — such as changing ideas or thoughts, expressions or gestures - may alter a feeling that is experienced. Emotion work can be done or enacted by individuals directed towards others, enacted on individuals by others, or done towards oneself to change one's own state of emotions.

Feeling rules share some of the cues from other sorts of social rules, where what one should feel, when and for how long are deemed appropriate for a given situation. Some of the complexities around the appropriate expression of emotions are leveraged by affordances of social media such as "liking" or reacting on Facebook, for example. Hochschild (Ibid., 567) argues that as much as feeling rules have aspects in common with other norms of conduct, changes in feeling rules results in a lack of clarity of what an appropriate reaction should be. What emerged from our field sites was that between generations, there are different expectations as to the norms of what to disclose, what to withhold and the appropriate way to react to the posts of others.

As we discuss later in the chapter, some of our informants revealed the tremendous effort they invest into displaying and circulating images in a way that is sensitive to the expectations of others within their family. As aspects of digital kinship, images of food and travel and the responses they invite constantly acknowledge family relationships. Prior to social media, family meals and family travel have emphasized bonding and ideals of family life. Circulating images of food and travel holidays in particular, contribute to sharing the experience of eating or travelling, activities that ideally would be experienced together. These digital practices of sharing are an extension of the offline, and greatly contribute to a sense of intimacy, especially for transnational families.

Food photography and social media has been previously discussed in relation to aesthetics and consumption, and travel photography has been 
discussed in relation to family photography as memory making and performance of idealized family life (Rousseau 2012; McDonnell 2016; Chalfen 2011; Kuhn 2007; Rose 2012). In this chapter, we demonstrate how the making and circulation of food and travel photos over social media also have culturally specific inflections that emerge through comparison.

\section{Co-present Eating: Sharing Food Moments}

As one of the most dominant genres of camera phone practices, sharing images of meals is integral to maintaining co-present intimacy and digital kinship. Sharing a meal is an act of intimacy and cultural significance in many places (Counihan 1999; Tierney and Ohnuki-Tierney 2012). Take, for example, this opening image by Tetsuo, a 38 -year-old freelancer, who lived with his wife and three children in a suburban area, around an hour by train from the center of Tokyo. Tetsuo often worked from home and was quite active in caring for their children and undertaking daily chores-including cooking. As his wife was not particularly fond of cooking, Tetsuo usually prepared the family meals. Often, he shared images of the food he and the children ate together while his wife was still at work, a gesture that allowed her to feel a sense of co-presence.

Tetsuo also used his mobile phone to discuss the evening's dinner menu with his wife. Based on their conversation and her advice given, he then went grocery shopping for everything needed for the evening meal. For the participants living with other family members in the same household, sharing information around the "meal" was a daily routine. This included sharing photos of food in addition to the prepared dish; photos also included the ingredients bought, and dishes bought outside the home, such as in restaurants.

In Tokyo, regardless of household structures and family members, the most common topic uploaded and shared was around travel. For example, Rika, the flight attendant who lived in Tokyo who was introduced earlier, used LINE to video call her mother while she was in the United States, travelling in Sedona, Arizona. Even though Rika's mother lived very close to her, she lived alone, so Rika tried to video call her as much as possible. "We can talk face-to-face using LINE video call. And it's free. When I was in Sedona, I wanted to tell my mother, 'I am in a place like this!' by showing the scenery and my face." Rika's calls were enjoyable as much as they were reassuring to her mother. Along with Facebook, she found LINE the easiest mode of communication with her daughter, while she was away, "It's nice. I can feel 

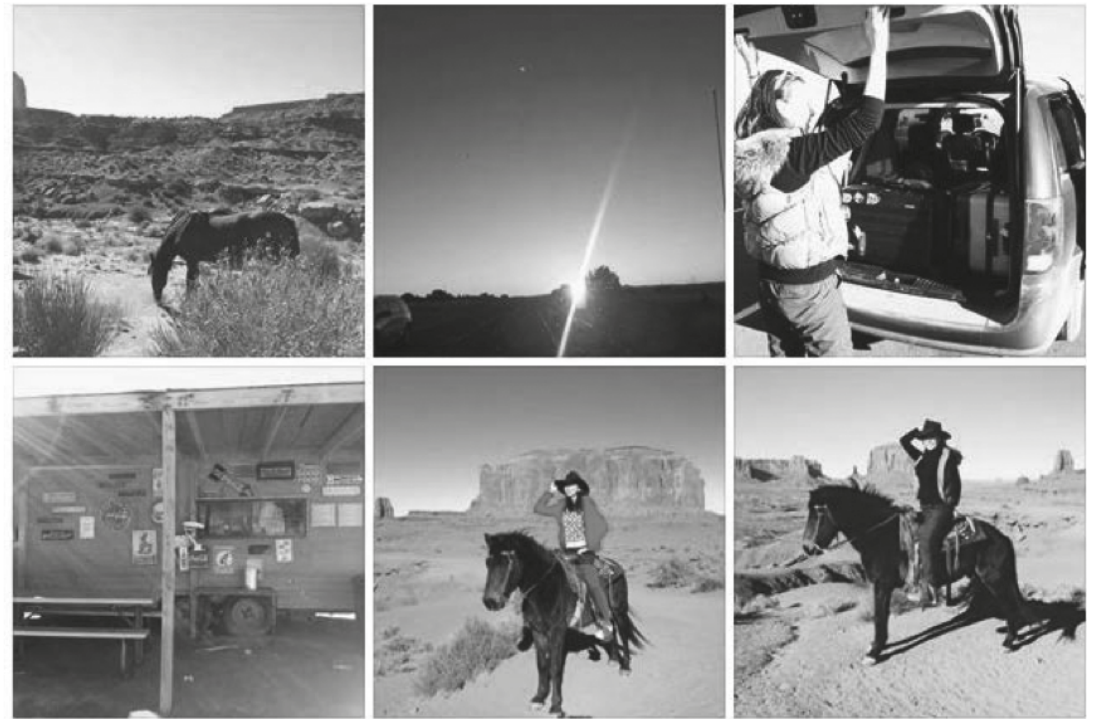

Figure 7.1: Rika's travel images

safe." Similar to the case of Rika, many participants explained the reason for sharing content related to their travels was that they wanted to share experiences they felt to be "extraordinary" with family members (Larsen 2005; Haldrup and Larsen 2003). They also wanted to keep other family members informed of their well-being. Travel photos operate effectively as a sense of friendly surveillance and the assurance of safety.

The majority of participants in Japan initiated contact with family members to coordinate or confirm schedules with one another via social media, rather than SMS. Take, for example, university student Shizuka who lived with her father, mother and younger sister in a condominium in the Tokyo area. Her busy schedule included studying, a part-time job, club activities, and catching up with her boyfriend. She often chatted with her family on LINE. She was not connected to her family on other social media platforms such as Instagram, Facebook and Twitter, but on LINE she communicated with them in a "family group." On her way home late at night, she would send a message to the family group on LINE to let them know what time to expect her. These kinds of gestures were reassuring to her mother, while her father stayed awake to let Shizuka in when she arrived home. Further, sharing updates around movements reassured family members of one's safety and assisted in coordinating schedules around meal planning.

Exchanging the image as a kind of information is as important as chatting for micro-coordination. Family members upload and share photos for the 
purpose of confirming safety, running errands, or coordinating calendars. At the same time, visualizing their day-to-day activities may serve to fulfill one's desire to be (socially) accepted.

Echoing Villi (2007), Gómez Cruz and Meyer (2012) who suggest that posting mundane photos of the everyday is not simply about showing mundaneness, but also the act of capturing and sharing the mundane is in itself stepping outside the mundane. The act of sharing a photo is also done in the hope that friends will see it on their timeline or newsfeed and will respond by "liking" the image. For example, travel and food photos are aesthetically pleasing and less confrontational forms of self- expression than sharing one's emotions.

The theme of "food-porn" has been observed in several contexts (McDonnell 2016). In Japan, there is an equivalent term meshi-tero where mesh $i$ is a meal, and tero is an abbreviated form of the word terrorism. Within close friendships, the term is used when friend(s) upload food photos, particularly during dinnertime or late at night. What makes these images meshi-tero is that they appear to be posted with the aim of appearing appetizing, while those viewing them are currently occupied with work or other tasks and are unable to leave to have a meal. Meshi-tero can be understood as a sign that the genre of "meal (food)" may have potential capacities to facilitate communication over social media in a routinized manner.

Although several of our participants in Melbourne were able to show instances of food photos posted by others on their Facebook or Instagram timelines, far less posted of images of food themselves. Yana, who appeared in the previous chapter, lived with her partner Nathan, who worked as a chef. Nathan considered himself a very private person, and although his cooking was outstanding - even when preparing meals for the family at home-he preferred not to display images of them to others. Yana also did not upload images of Nathan's cooking to Facebook, she says, "I just took pictures of it but this won't go on Facebook or anything like that but everyone at work has seen it but I won't post that because to me it's private." She preferred to show images on her phone to her friends at work where they could have a light- hearted chat about them, rather than "put them on display." Yana and Nathan illustrated a significant point about digital kinship and disclosure. By withholding images of Nathan's dishes, the intimacy of family space and family time was also maintained as private and not for the public display, consumption or gaze of others.

Circulating images of food and travel was much more important for others who have relatives and friends overseas. Stephen lived with his wife and teenage daughter. He had retired, but soon took up a part-time job in a fast 
food restaurant to keep himself busy. He moved to Melbourne in 1989, but he still visited his relatives, ex-navy colleagues, and former school friends in Malaysia and Singapore around once a year. He also used WhatsApp to chat with his friends overseas and he was the administrator of two Facebook pages, one for his ex-navy friends and one for his extended family. Stephen posted photos to both Facebook groups and he encouraged his ex-navy friends to post images to their page as well. He explained, "They can post what they're doing, where they've been, if the family is going somewhere, celebrations, that sort of thing, where we can connect as a family and as a group."

Stephen usually had his smart phone when his family went to dinner with his sister's family. Because they have lived in Melbourne for over 25 years, they usually tried new restaurants, rather than going to ones they had been frequented over the years. Although not a special occasion per se, Stephen would usually take a photo, particularly when the families were trying a new cuisine, and shared them on his profile page. Before owning the phone, he was using at the time of the research, Stephen only took family photos on holiday or visiting relatives overseas. Stephen posted both family outings and photos from within the home:

Family events, yeah, I do take photos, not many, just enough to remember the occasion ... Sometimes I post it on Facebook, but sometimes I just keep it in there (the phone). Sometimes I go outside and have a look at my plants I take a photo and post it. I want my family to have a look. I'm proud of my garden!

Several of the same groups of friends have visited Stephen and his family in Melbourne. Throughout these visits, Stephen was the main photographer and used his smartphone to take photos of his guests with his family at restaurants or at landmarks - especially if they were recognizably Australian-and shared them on his own profile, and also the ex-navy colleagues' page. When Stephen's family went on holiday, they would travel to Malaysia and other parts of South East Asia. Common holiday photos for Stephen and his friends were types of food, "like someone put they went to Korea, they had food they enjoy, this sort of thing. Especially when they travel." As well as keeping photos on his phone, Stephen backed them up to his desktop, a habit his wife was careful to ensure.

Drawing on John Urry's (2003) "tourist gaze," Haldrup and Larsen (2003, 25) explore family tourist photography through what they term the "family gaze." Employing a similar reflexivity as the tourist gaze, the family 
gaze draws attention to how sociality and social relations color the tourist perspective and photography. They suggest that the family gaze is "for acting out and framing active and tender family life for the camera. Family members and their performances make experiences and places extraordinary and full of enjoyable life" (Ibid.).

By approaching family photographic practices as a way of how families see the world and themselves, Haldrup and Larsen also emphasize that holiday photos do more than record keeping or documenting real experiences, they also "reveal more about the culture of imaginative families and idealized holidays than the people and places represented" (Ibid., 28). The family gaze takes a significant turn with mobile media discussed in relation to digital kinship. Family relationships shown through images posted more publically also creates ideals that are put on display, in the hopes that family members themselves may be able to live up to them.

As the administrator of his friends' page, Stephen also acted as content moderator. He encouraged family photos around food, travel and domestic life, but he discouraged his friends posting "rubbish" and "clutter," jokes that might be considered offensive, political opinions, and shares he saw as irrelevant. When they did appear, he removed these kinds of posts from the group. By encouraging photos of family life on the group page, Stephen also acknowledged the normativities around ideal family relationships as part of their shared identity as former colleagues.

A notable point from our case studies is that although posting photos was more typical for younger participants, posting travel and food photos was common across gender. Our observation challenges some of the assumptions around emotion work as well as family photography as being primarily the responsibility of women and mothers in particular. DeVault $(1999,56)$ draws attention to the different ways that women work to produce comfort within the family, from facilitating conversation about another family member's day, to preparing food as an expression caretaking.

Similarly, in the literature on family photography, mothers are emphasized as assuming the primary role in family photography making, curation and storage (Chalfen 1987; Rose 2003; Janning and Scalise 2015). These same authors also assert that as an extension of motherhood, mothers take responsibility for taking photos at key instances, organizing photos into albums and selecting and placing photos in frames to display in the home, where each of these acts serve to represent the family and idealized family life. Yet smartphones with high quality inbuilt cameras may represent a shift in the gendered nature of these practices, where digital kinship recognizes the efforts of maintaining relationships made by both men and women in the family. 

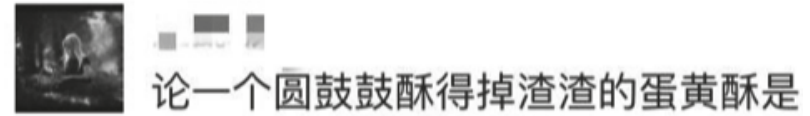
如何诞生的 @

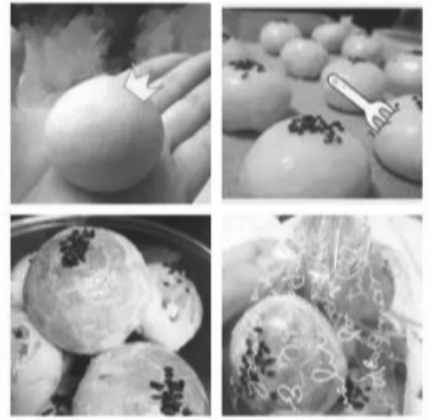

252 day(s) ago

Figure 7.2: WeChat moments, sharing food in Shanghai

In China, various genres of photos are circulated on WeChat. Food, travel and babies are among the most popular categories to appear as "Moments." Again, food and family meals are culturally important, and university students who participated in our research posted images of food regularly. 25-year-old Yi, for example, was a senior student at a university in Shanghai. She was particularly fond of sharing her homemade traditional Chinese dishes over digital media. Yi also considered herself to be quite shy, she did not share photos she considered too revealing of her personal life, and she only posted images once every two to three months; comparatively less often than Japanese and Australian participants. Yi explains, "I love cooking. I felt it meaningful to share something made by myself."

Figure 7.2 shows an image of Chinese snacks Yi prepared and then shared as WeChat "Moments." When Yi shared an image, she took several photos whilst preparing her dishes, which also enhanced her enjoyment of cooking. Every time Yi displayed a new post, her mother "liked" it, which demonstrated her support for her daughter's hobby. Sometimes, Yi also shared photos of her cooking in their family WeChat group.

Historically, food has also been a habitual way of greeting in Chinese society. On meeting, it is usual for familiars to ask: "Have you had your dinner yet?" as a daily greeting (similar to the way the weather is the subject of small talk for the British). Sharing photos of food with family 


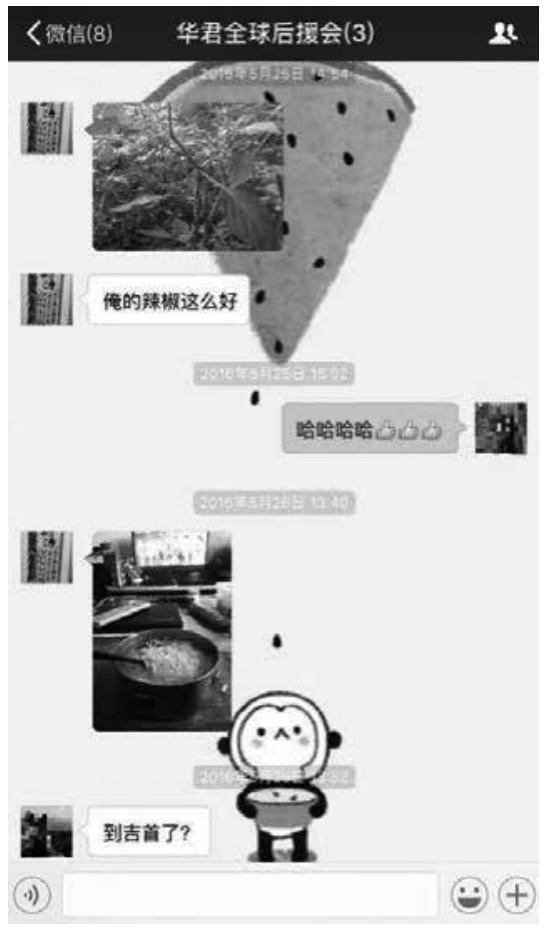

Figure 7.3: Chun's shared pictures

members is therefore a mundane practice on WeChat that reports the well-being of the person posting. Tiffany, who was introduced earlier, maintained a habit of sharing photos of food with families. "I did that just for fun, and to let them not be worried about my health." Another interviewee, 28-year-old student Chun, also shared a screenshot of her family sharing photos of food.

In this screenshot from Chun's phone, her father has shared two images. One is of his homegrown chili plant and the others show noodles he had cooked. By sharing these two photos, Chun's father conveyed two messages: firstly, that he had already arrived at home, and secondly, he was having a nice lunch. Notably in the second photo posted by Chun's father, he shared both the location and the dietary information with his wife and daughter, which is a typical example of mundane intimacy on digital media in the Chinese context. Images sent that reveal other useful information-such as the father's location and his dietary requirements - also reflect Miller et al.'s (2016) observation that due to social media, communication has become more visual. 


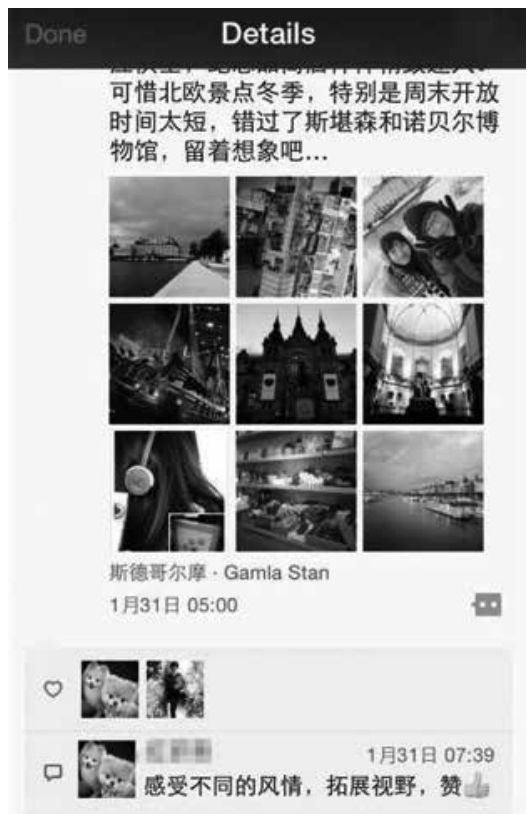

Figure 7.4: Jia's images on holiday

\section{Co-present Mobility: Sharing Travel Experiences}

According to participants who regularly share travel photos on WeChat, sharing photos of trips on social media was also a practice to commemorate life events. And by sharing travel photos in Moments, WeChat friends, including family members, could see the location as well as the "mood" of the person sharing, which can be read as an indication that the person is safe, especially when that person is quite young.

Jia, a 24-year-old young woman frequently shared travel photos. As a student who majored in tourism management, she liked travelling and enjoyed nature. During a trip to Europe, she posted updates to WeChat Moments almost every day.

Jia went on the European trip with her cousin Bo. The screenshot above shows several photos she posted of scenery in Stockholm. These images received the most "likes" from both her and Bo's mothers. Notably, Bo's mother reflected, "It was the first time for these two kids to travel abroad alone. To be honest, we've been worried about them." And Jia's mother described, "It is really convenient and comforting for us to find their travel photo in Moments, seeing them doing well and enjoying their time there." In addition to sharing travel photos in Moments, which is more public, 
some participants chose to directly share travel photos with their families in family groups on WeChat.

Qin and Jun had one daughter who was 25-years-old. Qin, Jun and their daughter interacted frequently on their family WeChat group. Their daughter shared a photo of a sunset during her trip with her parents in their family WeChat group. She had gone to Korea with two other friends and her parents felt relieved to receive her messages as well as seeing that she was enjoying her trip.

As we illustrate, families who live within close proximity and also for transnational families, the smartphone as a domestic technology plays a key role in how relationships are constituted and maintained, not only through pictorial depiction of the home and home life, but also through various uses of the smartphone within home life. These include organizing and coordinating daily tasks and routines, for capturing and sharing images of mundane and more eventful activities, and for research and entertainment. Hjorth $(2008,93)$ further asserts that the mobile phone is also "firmly embedded in what it means to experience place, co-present or not."

Doreen Massey's (2005) thoughts on locality have been influential for Hjorth and Pink, where she suggests a sense of locality is always mediated. For example, what constitutes "home" is mediated by memories infused with our sense of identity (Hjorth 2008, 94; Hjorth and Pink 2014). Place acts as "an organizing concept with fluid boundaries through which we can view and consider different configurations of online/offline combinations and the threads of sociality and visuality that traverse them" (Hjorth and Pink 2014, 46). By focusing on "emplacement" and co-presence, they also draw attention to where people, images, and technologies are always situated, in movement, and part of and constitutive of place (Ibid., 54). For transnational families, this is quite literal, where shared images are also, as Pink $(2011,7)$ describes, images that "are in movement as material or digital 'things' that travel from one locality to another."

\section{Conclusion}

This chapter has contextualized the exchange of images on social media, travel photos and food photos in particular within digital kinship as a mode of doing some of the work of the "family." Hochschild's (1979) notions of feeling rules and emotion work have been particularly helpful in relation to digital practices. Feeling rules as the norms and expectations around the appropriate ways to react, and when are first learned within 
the family (Thompson and Meyer 2007, 25). Images posted to social media act as cues from which the responses elicited display a range of emotions, from acknowledgement to relief.

As a form of "staying in touch," sharing photos can be compared to mutual gift exchange and generalized reciprocity, a theme that was explored in Chapter 4. And as discussed in Chapter 5, Baldassar (2007) identifies different kinds of care giving - from routine, the day-to-day form of care that is characterized by regular contact, and ritual care giving, the marking of special occasions and makes up "kinwork." For migrant families in particular, digital devices are used to maintain relationships in different ways including sending, sharing and displaying images, but also, as Baldassar, Baldock and Wilding (2006) argue, different forms of communication have different consequences for the family relationships involved.

One of those consequences is that more routine exchanges increase obligations and expectations, for more ritual exchange around significant events and for more visits. We have found that one of the ways family members navigate these expectations-either actual or perceived-is through withholding, a theme that is explored further in the next section of the book. Family members don't necessarily withhold communication, but they withhold what can be seen as "material evidence" of their lives and lifestyles "away."

Finally, Mason (1996) draws a distinction between the ideas of caring about, and the feelings and emotions of caring, and caring for as the actions, efforts and forms of labor that are invested in active caring. The circulation of travel and food photos are strongly resonant in relation to both caring about and caring for, which takes into account the family and family practices as represented in photos and in the acts of sharing and displaying them. Kinship through digital media practices also highlights the tremendous efforts that individuals invest into maintaining family relationships, whether in the same locality through forms of micro-coordination or through showing care at a distance.

\section{References}

Baldassar, Loretta, Cora Baldock, and Raelene Wilding. 2006. Families caring across borders: Migration, aging and transnational caregiving. New York: Springer. _.2007. "Transnational families and the provision of moral and emotional support: The relationship between truth and distance." Identities: Global Studies in Culture and Power 14 (4): 385-409. DOI: 10.1080/10702890701578423. 
Chalfen, Richard. 1987. Snapshot versions of life. Wisconsin: University of Wisconsin Press.

Chalfen, Richard. 2011. "Doing family photography: The domestic, the public and the politics of sentiment." Visual Studies 26 (2): 176-178. DOI: 10.1080/1472586X.2011.571905.

Counihan, Carole M. 1999. The anthropology offood and body: Gender, meaning, and power. New York: Routledge.

DeVault, Marjorie L. 1999. “Comfort and struggle: Emotion work in family life." The Annals of the American Academy of Political and Social Science, 561 (1): 52-63.

Erickson, Rebecca J. 2005. "Why emotion work matters: sex, gender, and the division of household labor." Journal of Marriage and Family 67 (2): 337-351. DOI: 10.1111/j.0022-2445.2005.00120.x. Accessed 10 March 2018.

Gómez Cruz, Edgar, and Eric T. Meyer. 2012. "Creation and control in the photographic process: iPhones and the emerging fifth moment of photography." Photographies 5 (2): 203-221. DOI: 10.1080/17540763.2012.702123.

Haldrup, Michael, and Jonas Larsen. 2003. "The family gaze." Tourist Studies 3 (1): 23-46. DOI: 10.1177/1468797603040529.

Hjorth, Larissa. 2008. "Being real in the mobile reel: A case study on convergent mobile media as domesticated new media in Seoul, South Korea." Convergence 14 (1): 91-104. DOI: 10.1177/1354856507084421.

Hjorth, Larissa, and Sarah Pink. 2014. "New visualities and the digital wayfarer: Reconceptualizing camera phone photography and locative media." Mobile Media \& Communication 2 (1): 40-57. DOI: 10.1177/2050157913505257.

Hochschild, Arlie R. 1979. "Emotion work, feeling rules, and social structure." American Journal of sociology 85 (3):551-575. DOI: 10.1086/227049. Accessed 2 March 2018.

Horst, Heather, and Daniel Miller. 2012. "Normativity and materiality: A view from digital anthropology." Media International Australia 145 (1): 103-111.

Janning, Michelle, and Helen Scalise. 2015. "Gender and generation in the home curation of family photography." Journal of Family Issues 36 (12): 1702-1725. DOI: 10.1177/0192513X13500964.

Kuhn, Annette. 2007. "Photography and cultural memory: a methodological exploration." Visual Studies 22 (3): 283-292. DOI: 10.1080/14725860701657175.

Larsen, Jonas. 2005. "Families seen sightseeing: Performativity of tourist photography." Space and Culture 8 (4): 416-434. DOI: 10.1177/1206331205279354.

McDonnell, Erin M., 2016. "Food Porn: The conspicuous consumption of food in the age of digital reproduction". In Food, Media and Contemporary Culture: The Edible Image, edited by Peri Bradley, 239-265. New York: Springer.

Mason, Jennifer. 1996. "Gender, care and sensibility in family and kin relationships." Sex, Sensibility and the Gendered Body, edited by Lisa Adkins, and Janet Holland, 15-36. London: Palgrave Macmillan. 
Massey, Doreen. 2005. For Space. London: Sage.

Miller, Daniel, Elisabetta Costa, Nell Haynes, Tom McDonald, Razvan Nicolescu, Jolynna Sinanan, Juliano Spyer, Shriram Venkatraman, and Xinyuan Wang. 2016. How the world changed social media. London: UCL Press.

Pink, Sarah. 2011. "Sensory digital photography: Re-thinking 'moving' and the image." Visual Studies 26 (1): 4-13. DOI: 10.1080/1472586X.2011.548484.

Rose, Gillian. 2003. "Family photographs and domestic spacings: A case study." Transactions of the institute of British Geographers 28 (1): $5^{-18}$. DOI: 10.1111/1475-5661.00074.

-2012. Doing family photography: The domestic, the public and the politics of sentiment. Kent, UK: Ashgate Publishing Ltd.

Rousseau, Signe. 2012. Food and social media: You are what you tweet. Lanham: Altamira Press/Rowman \& Littlefield.

Thompson, Ross A., and Sara Meyer. 2007. "Socialization of emotion regulation in the family." In Handbook of Emotion Regulation, edited by James Gross, 249-268. New York, London: The Guilford Press.

Tierney, R. Kenji, and Emiko Ohnuki-Tierney. 2012. "Anthropology of food." In The Oxford Handbook of Food History, edited by Jeffrey M. Pilcher, 117-134. Oxford: Oxford University Press.

Urry, John. 2003. Global Complexity. Cambridge. UK: Polity Press

Villi, Mikko. 2007. "Mobile visual communication: Photo messages and camera phone photography." Nordicom Review 28 (1): 49-62. 